\title{
Development of Chengdu and sustainable utilization of the ancient Dujiangyan Water-Conservancy Project
}

\author{
XIAORONG HUANG ${ }^{1,2}$, JINJUN YOU ${ }^{3}$, PENGPENG YANG ${ }^{2}$ \& XUERUI CHAI ${ }^{2}$ \\ 1 State Key Laboratory of Hydraulics and Mountain River Engineering, Sichuan University, Chengdu, 610065, China \\ hxiaorong@scu.edu.cn \\ 2 College of Water Resource \& Hydropower, Sichuan University, Chengdu, 610065, China \\ 3 China Institute of Water Resources and Hydropower Research, Beijing, 100044, China
}

\begin{abstract}
The Dujiangyan Water-Conservancy Project is a great water irrigation works in Chinese cultural history, which led the Min River water to the vast Chengdu Plain, and created fertile and pretty "land of abundance". Now Chengdu is facing increased water demand stress due mainly to rapid urbanization. This paper first analyses the available water resources of Chengdu based on historical hydrological data from 1964 to 2008 . The results show that the average annual water resources were 8.9 billion $\mathrm{m}^{3}$ in 1986 and 7.9 billion $\mathrm{m}^{3}$ in 2008 under various environmental conditions. The future tendency of water demand in city development planning is predicted by the Policy Dialogue Model (PODIUM). Finally, the strategies for water resources exploitation accompanying the sustainable development pattern are studied. The result illustrates that rational and careful management are required to balance the gap between water supply and demand.
\end{abstract}

Key words Dujiangyan Water-Conservancy Project; urbanization; water demand

\section{INTRODUCTION}

Dujiangyan Project is a great water irrigation works, as famous as the Great Wall in Chinese cultural history, located at the join between the middle reach and upper reach of the Min River of the Chengdu Plain (Tan, 2009). In 256 BC, the great works were built under the leadership of Li Bing, governor of Shu Shire during the Qin dynasty. It is the only preserved major water irrigation works characterized by a long-standing history and water diversion without a dam.

The hydraulic structures of the Fish Mouth, Feisha Dam, and Baopingkou Aqueduct are designed to work together perfectly given the natural situation. Problems such as the free-flow diversion of river water, free-flow sand discharge as well as the control of the intake water volume have been solved scientifically, due to the solid foundation which has been laid for the long preservation of the Dujiangyan Project. For the last two thousand years, the ancient weir project has diverted the Min River water to the vast Chengdu Plain, and created the fertile and pretty "land of abundance" (Peng, 2004a). The layout of Dujiangyan Project is shown in Fig. 1. Chengdu is an extremely large city in the southwest China, with an area of $12400 \mathrm{~km}^{2}$ and annual rainfall of 900-1300 mm. The location and a sketch map of Chengdu are shown in Figs 2 and 3. The completion of Dujiangyan Project brought rapid development and progress to Chengdu. In the Donghan Dynasty (22-220 AD), the population of Chengdu increased to more than 400000 (as described in the Huayang State Record), in the Tang Dynasty (618-907 AD) it rose to 580000 , and in 2007, the population of Chengdu City downtown area was more than 4.5 million (Annual Statistic Book of Chengdu in 2008).

Impacted by climate change and human activities, the inflow at Fish Mouth of Dujiangyan Project has become less in recent years. The annual mean inflow in the 10 years 1996-2005 was 12.86 billion $\mathrm{m}^{3}$, cf. an annual mean inflow of 14.89 billion $\mathrm{m}^{3}$ in the 37 years from 1959 to 1995 . The annual runoff at the Fish Mouth cross-section of the Min River has been decreasing at $1.78 \mathrm{~m}^{3} / \mathrm{s} /$ year over the past 50 years (Huang et al., 2014). In contrast to this, the renewed urbanization progress and social and economic development requires a yearly increase of water intake volume from the inner and outer river of Dujiangyan Project. The water intake volume has been more than 10 billion $\mathrm{m}^{3}$ in recent years, the highest diversion volume (1993) was up to 11 billion $\mathrm{m}^{3}$ and the annual mean water intake volume is 9.40 billion $\mathrm{m}^{3}(1959-2005)$. The total water volume consumed by Chengdu in 2000 is 4.30 billion $\mathrm{m}^{3}$, with $77.7 \%$ of the volume from Dujiangyan Project (Chengdu Water Resources Bulletin, 2000, 2007). The decrease of inflow from 


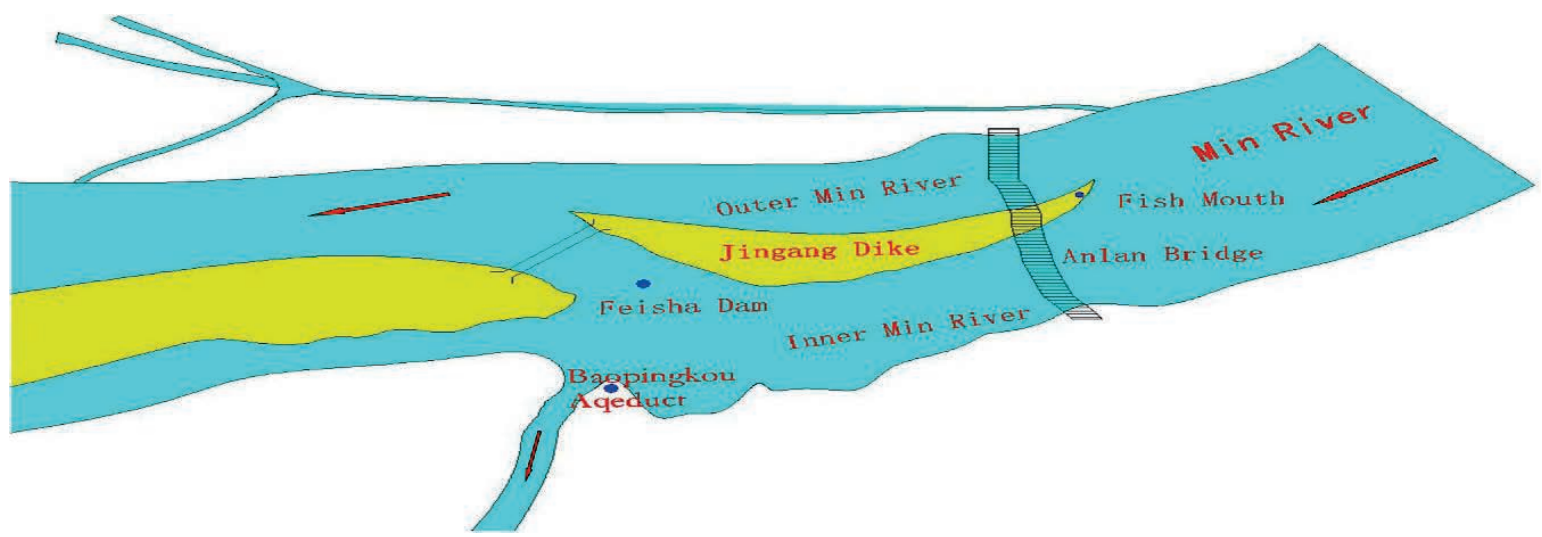

Fig. 1 Layout of Dujiangyan Water-conservancy Project.

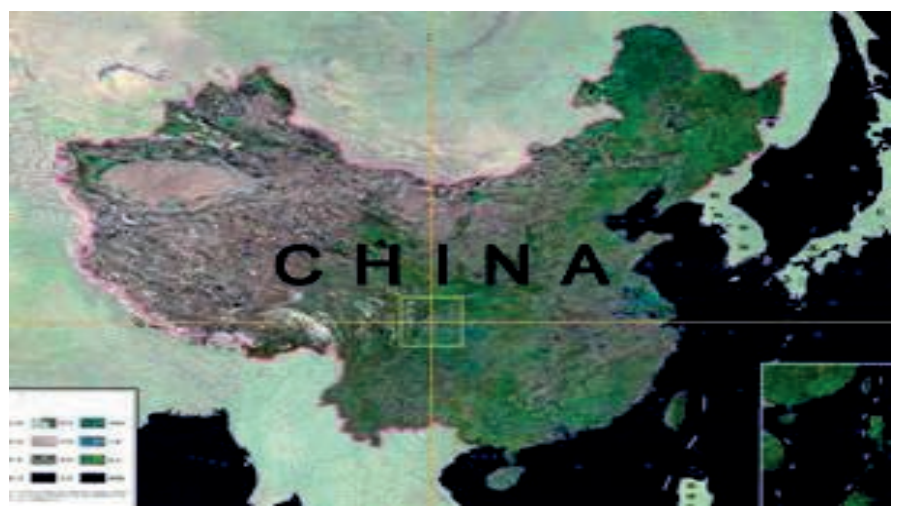

Fig. 2 Geographical location of Chengdu.

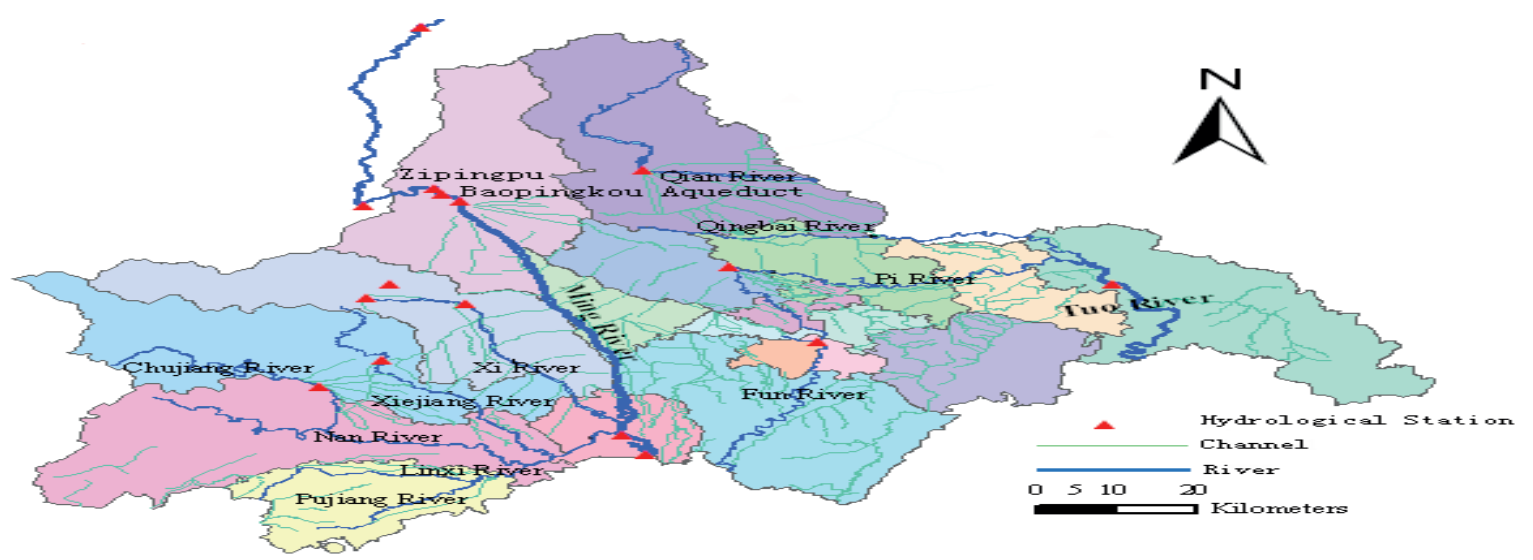

Fig. 3 Sketch map of Chengdu area.

the upstream of Min River and the increase of water intake volume from the inner and outer river of Dujiangyan Project, and increased municipal water consumption volume have created a more and more obvious contradiction between water supply and water demand for each sector (Liu et al., 2009). Water for agriculture will be further taken up by industry and town residents, the grain output appears to be reduced; the competition for water volume between environmental protection and production will be more serious than at any other time. Almost $100 \%$ of the Min River flow in the low flow period in a year, and in the normal flow period (October to following May) is diverted into the Dujiangyan Project, resulting in appearance of 7-8 months' of zero-flow in a $72.70 \mathrm{~km}$ stretch of the middle reach of the Min River main stream (Huang et al., 2014).

The Dujiangyan Project is the lifeline for Chengdu's survival and development. The exceptionally favourable natural geographic advantages and engineering condition bring about the 
high water intake proportion characteristics at the intakes of inner and outer river. The Min River is now in a state of over-exploitation. For the purpose of scientific and rational utilization of the ancient Dujiangyan Project, coordination of the relationship between the economy, society and eco-environment is of great importance. Sustainable utilization of Min River water resources and rational regulation of the Dujiangyan Project are preconditions of sustainable of a Chengdu (Peng et al., 2004b). Therefore, this paper focuses on three aspects. The first is to predict the future water demand of Chengdu City scientifically and rationally, based on the master development plan of Chengdu, including prediction of water demand for agriculture, industry and urban life according to the specific industrial and agricultural development indices for socio-economic and environmental development in the future with consideration of social change, such as population increase, advances in water utilization technology, irrigation water utilization coefficient rise, etc. The second is to coordinate the relationship between the water resources supply and regional economic development arrangement, set up relevant water allocation models, consider factors such as water resources demand and water supply conditions, distribute various available water sources rationally among regions and sectors for water utilization, and guarantee the health of the Chengdu river water systems. The third is to propose countermeasures.

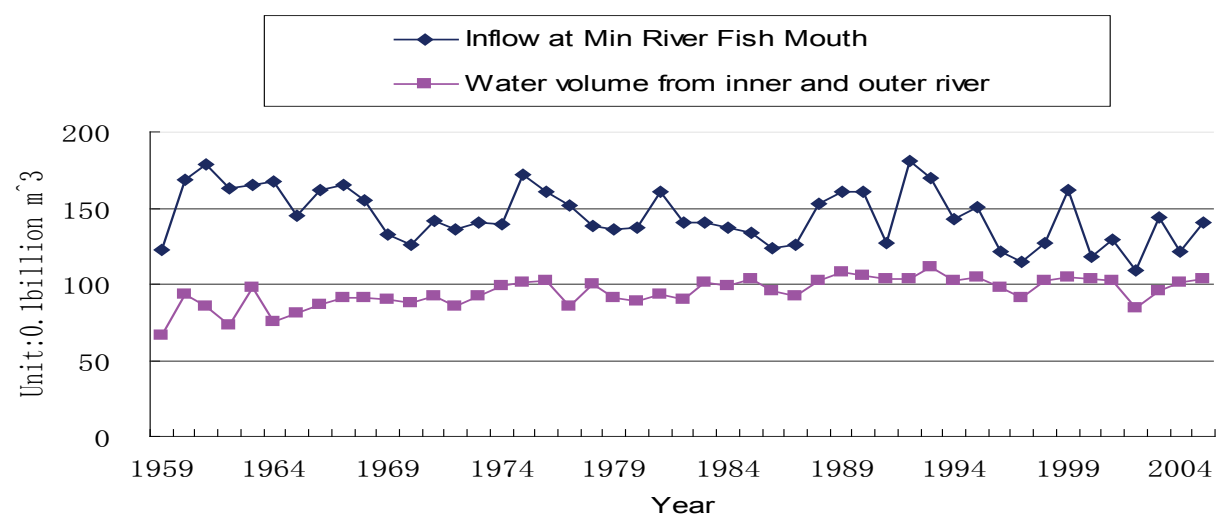

Fig. 4 Inflow at Min River Fish Mouth and water volume into Dujiangyan Project.

\section{WATER RESOURCES DEMAND PREDICTION}

The prediction of water demands is the fundamental basis of water resources planning and management. Water resources demand prediction includes three parts: the prediction of economic and social development, economic and social water demand and ecologic environment water demand (Huang et al., 2007). The prediction of economic and social development can be based on Chengdu City development planning.

A model for social water demand prediction was developed based on PODIUMSim (the policy dialogue simulation model), an application software put forward in 1999, improved and perfected by the International Water Management Institute for inter-connected simulation of water resources development and utilization, and food safety. This model can provide water resources supply and demand balance analysis in future regions under various policies and hydrological conditions, including:

(a) Proposal of alternatives for irrigation and rain-supported agriculture production in specific areas.

(b) Proposal of yearly water supply development plan for seasonal agricultural water demand development and alternatives for household and industrial water demand.

The industrial production value, irrigation areas, crop pattern, production value of fishery, forestry etc., are taken for detailed agricultural and urban/industrial water demand forecasting. Water demand for ecological environment improvement is predicted with the instream and outstream ecological environment water demands in accordance with the requirement for recovery and beautification of the ecology and environment. The instream eco-environmental water demand is calculated based on hydrological methods while the outstream eco-environmental water demand is 
predicted based on the index and scale of eco-environmental requirement, including the increase of water area, forestation and urban sanitation.

The predication shows that the GDP of Chengdu City in 2030 will rise to 3317.27 billion RMB Yuan, from 332.42 billion RMB Yuan of 2007, and the population will rise to 16.55 million from 12.58 million. The water demands in 2020 and 2030 will amount to 7.66 and 8.67 billion $\mathrm{m}^{3}$, respectively (Table 1).

Table 1 Water demands forecasting in Chengdu (billion $\mathrm{m}^{3}$ )

\begin{tabular}{llllll}
\hline Year & Domestic & Industry & Agriculture & Environment & Total \\
\hline 2020 & 0.82 & 3.48 & 3.08 & 0.28 & 7.66 \\
2030 & 0.99 & 4.47 & 2.88 & 0.33 & 8.67 \\
\hline
\end{tabular}

\section{WATER RESOURCES ALLOCATION}

Water resources allocation is carried out under the rules and realistic requirements considering equally the ecologic environment and water resources utilization. Eco-environmental objectives refers to providing the necessary ecologic environment water to keep the rivers healthy in Chengdu. The water resources utilization objective refers to seeking the minimum water shortage, and reasonable water allocation for compromised benefit among the region's sectors. The water resources allocation model both describes the hydrologic conditions and quantifies the water supply available for industry, agriculture, and domestic and public uses. This model can generalize the actual water system into nodes and hydraulic links, and form a network system by such links and nodes. The network system can reflect the main characteristics of the actual system as well as the relationship among the components, and describe the relationship through variables and parameters. The network system can work out results of the water supply and demand balance and the water volume balance based on the regular simulating calculation technique (You et al., 2005). In brief, this model follows three fundamental rules: (1) Reasonable project regulation; (2) Distinct relationship of water volume balance; (3) Analysis of long-term series data. The hydraulic network of the water allocation model for Chengdu is shown in Fig. 5.

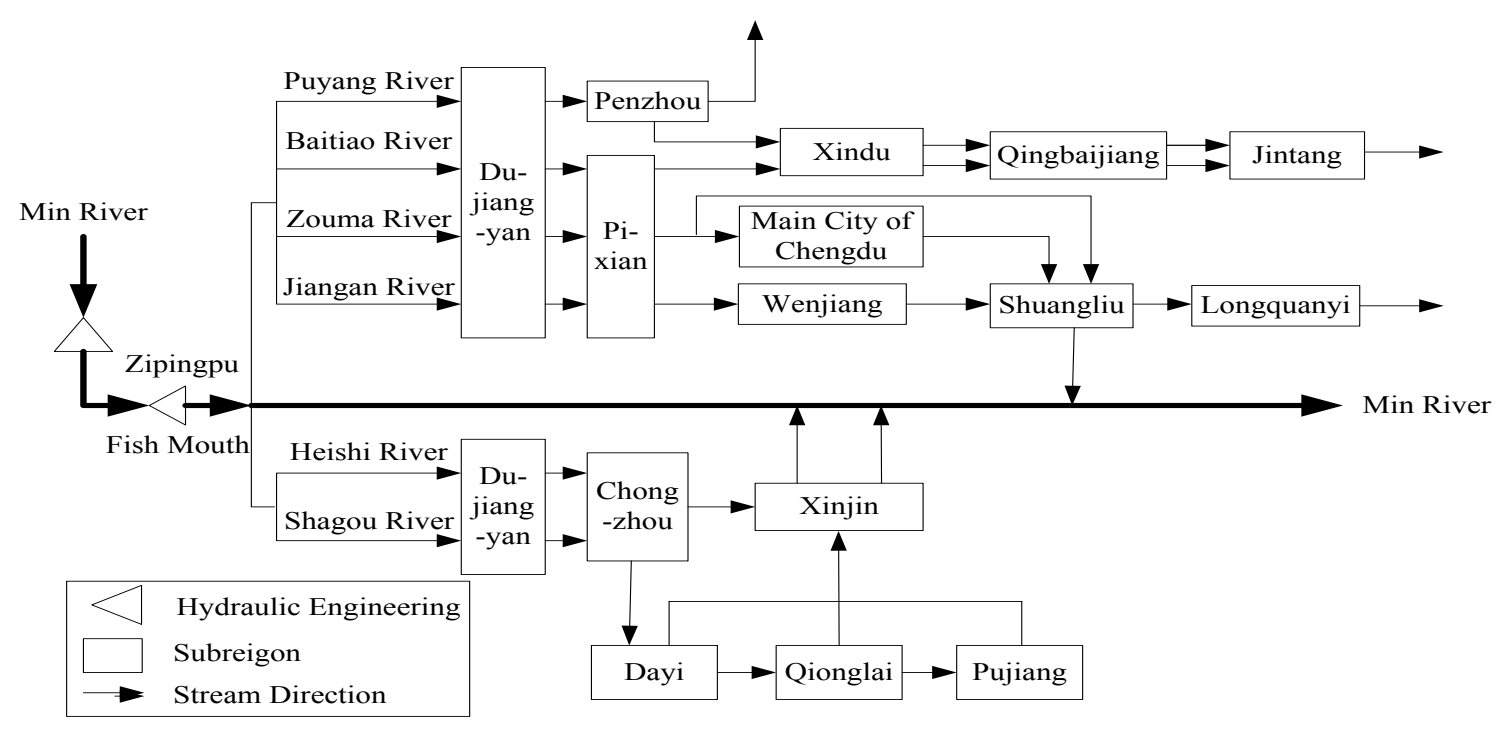

Fig. 5 Conceptual water resources network of Chengdu.

According to the water resources allocation scheme, the future local surface water resources supply volume for Chengdu will increase to 2.56 billion $\mathrm{m}^{3}$ in 2030 from the current 1.65 billion $\mathrm{m}^{3}$, basically amounting to the top limit of local available water resources. With the increase of total water consumption volume, the utilization of water volume from Dujiangyan Project will be further increased to 5.72 billion $\mathrm{m}^{3}$ in 2030 from the current 3.42 billion $\mathrm{m}^{3}$, covering $69 \%$ of the 
total surface water supply. In addition to enlargement of the total volume, the main objective of water supply for the Dujiangyan Project system will be a change from agricultural to urban water use, and the proportion of urban water supply in the Min River system will rise to $64 \%$ from the current $36 \%$ (Fig. 6).

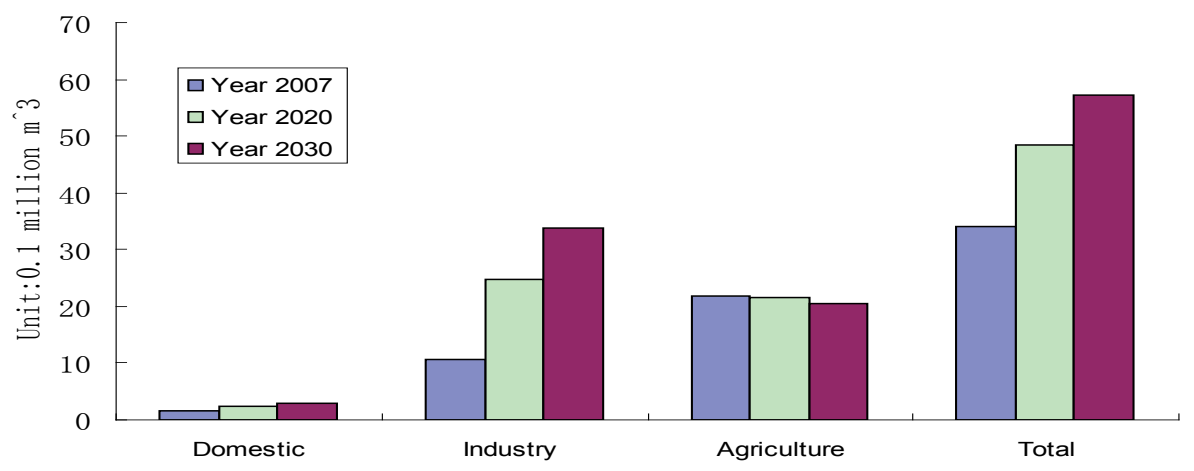

Fig. 6 Water supply volumes of inner and outer river in current year and planned level year.

\section{CONCLUSIONS}

(a) Min River is the main source for Chengdu water supply at present and in the future. Available water resources for Chengdu must be proposed on the basis of rational allocation of Min River water resources. Water right is the precondition of regional optimal water use and satisfy the basic requirements for the ecosystem and environment.

(b) Market mechanisms should be applied to realize the higher efficiency of water distribution.

(c) Efforts must be made to support development and utilization of local water resources to relieve the impact on the ecosystem caused by over-utilization of the ancient Dujiangyan Project.

The simulation shows that the eco-environmental flows at the main river control stations on Min River and in Dujiangyan irrigation area are in high guarantee degree while the eco-environment flows in parts of small tributaries are in low guarantee degree, and this will be more prominent in 2030 planned level year.

Though the water-saving level of industry and agriculture of Chengdu will keep rising in the future, the greater increase of water demand will lead to the increase of the proportion of water supply from Dujiangyan Project. The optimized water resources allocation will ensure the ecoenvironmental flow of the main river sections, however, the sustainable utilization of the ancient Dujiangyan Project still faces severe challenges.

Acknowledgements This study was financed by the Science and Technology Support Program of Sichuan (2013SZ0102). Funding also came from the Open Research Fund of State Key Laboratory of Simulation and Regulation of Water Cycle in River Basin (IWHR-SKL-201207). Thanks are also given to the Bureau of Water Resources of Chengdu and the work team for water resources integrated planning of Chengdu city.

\section{REFERENCES}

Chengdu Local Record Compilation Committee (2001) Chengdu City Hydro-power Record. Chengdu: Sichuan Dictionary and Works Press.

Chengdu City Statistic Bureau (2008) Annual Statistic Book of Chengdu. Beijing: China Statistic Press.

Huang, X.R., et al. (2007) Key Technical Theory and Practice on River Basin Water Resources Planning. Zhengzhou: Yellow River Hydro-power Press.

Huang, X.R. et al. (2014) Impact of climatic change on streamflow in the upper reaches of the Minjing River. Hydrological Sciences Journal 59(1-2), 154-164.

Liu, L.J., Bie, J.X. and Qin, S.Y. (2009) The strategic choice for the sustainable utilization of water resources in the water supply area of Dujiangyan. Si Chuan Water Conservancy 5, 41-44.

Peng, S.M. (2004a) Dujiangyan: a perfect example of sustainable development. China Water Conservancy 18, 15-18.

Peng, S.M., Xiao, F. and Sun, Y.H. (2004b) Research on the strategy of sustainable development of Dujiangyan water conservancy. Bejing :China Science Press.

Tan, X.M. (2009) Dujiangyan Project History. Beijing :China Hydro-power Press.

You, J.J. et al. (2005) Simulation of water resources system based on rules. Journal of Hydraulic Engineering 36(9), $1043-1049$. 